\title{
Resource-loaded piping spool fabrication scheduling: material-supply-driven optimization
}

\author{
Jing Liu, Meimanat Soleimanifar and Ming Lu*
}

\begin{abstract}
Background: As offsite prefabrication and modular construction continue to gain momentum into the future, material supply chain becomes increasingly complex for modern construction projects. Pre-engineered material supply presents itself as a driver for planning crew installation operations on site that involve skilled labor and heavy equipment.

Methods: This paper proposes a framework for implementing the material-supply-driven project planning and control optimization approach to deal with material delays that take place at the piping spool fabrication shop. Design drawings, contract deadlines, resources availability and material supply patterns are extracted from a real oil and gas expansion project to validate the proposed implementation methodology.

Results: An interactive Gantt chart with information on activity start time, duration, and allocated resources is generated to visualize the optimization outcome. In connection with the resource-constrained schedule, material supply-demand patterns over project duration are also visualized.

Conclusions: These two forms of visualizations provide insightful decision-making support in coping with material delay while fulfilling project objectives. Ultimately, material-supply driven crew job schedules in correspondence with particular objectives and implementation strategies can be generated, ready to guide project execution.
\end{abstract}

Keyword: Scheduling, Resources, Constraint programming, Optimization, Spool fabrication, Supply chain management, Material information management, Modular construction, Fabrication

\section{Background}

The construction industry is a vital component to the national economy for many countries. In Canada, 2015, construction industry accounted for $7.18 \%$ of the Gross Domestic Product (GDP) and provided $7.64 \%$ of the national employment (Statistics Canada 2016a; Statistics Canada 2016b). The construction industry in the province of Alberta is unique due to the high proportion of mass capital projects, extreme cold weather, labor shortage, and special contractual strategies. Over the past few decades, modular construction method has been widely implemented in lieu of the conventional stick-build method in developing industrial projects across the globe.

Haas et al. (2000) defined the industrial modular construction as "the preconstruction of a complete system

\footnotetext{
* Correspondence: mlu6@ualberta.ca

Department of Civil and Environmental Engineering, University of Alberta, Edmonton, $\mathrm{AB}$, Canada
}

away from the job site that is then transported to the site". Figure 1 shows typical processes in building an industrial plant by modular construction technology, consisting of spool fabrication, module yard assembly, and on-site installation. Pipe spools are first fabricated in fabrication shops from a large amount of raw pipe and pipe fittings (e.g., elbow, tee, flanges). These pipe spools are then transported to module yard for assembling or directly to site for installation. In the process, large-scale of complex engineered components, manufacturing offsite prefabrication and preassembly processes are entailed (Taghaddos et al. 2012). For this reason, the timely delivery of raw materials and offsite pre-fabricated components is crucial to the success of industrial modular construction projects.

However, the majority of these raw materials and prefabricated components are increasingly sourced from offsite or even offshore fabrication facilities. The balance 


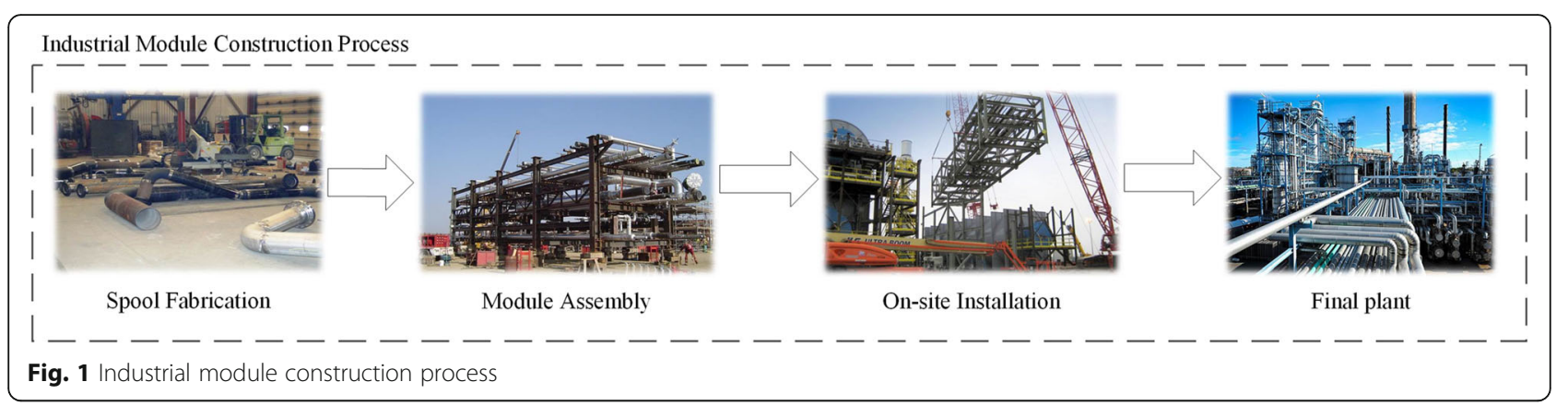

between material supply and production plan needs to be delicately maintained in order to minimize the idling time of material and labors, and the project duration (Koskela et al. 2002). The concept of supply chain management (SCM) is to integrate all the activities related to the flow and transformation of products from raw material to end user, in order to better satisfy the needs of end-customers and benefit all members in the chain (Walsh et al. 2004). However, due to the broad variability in field productivity and the difficulty in predicting material demands by field activities, it is more challenging to achieve efficiency in supply chain management in the construction industry than in the manufacturing industry (Dubois and Gadde 2002; Tommelein et al. 2003). The complicated material supply chain in the construction industry generally makes just-in-time material delivery practically impossible. Song et al. (2009) found that $20 \%$ of the spools in fabrication shops and $60 \%$ of equipment modules in module assembly yards experienced material shortages. Thomas and Sanvido (2000) concluded that poor material management could cause 50 to $130 \%$ schedule slippage by conducting three case studies.

The optimization of supply chain management in logistics or operation research (OR) aims to streamline the material flow by removing all the non-value adding processes and material wastes (Arbulu and Ballard 2004). The optimization objectives are generally set to minimize the inventory cost, or minimize buffer sizes and time of material waiting prior to being further processed (Tserng et al. 2006; Walsh et al. 2004; Xu et al. 2016). However, research in supply chain optimization in the context of construction planning has yet to address the project scheduling problem by (1) incorporating the supply of materials as explicit constraints alongside labor constraints and technology constraints; and (2) simultaneously achieving the efficiency of supply chain management and the efficiency of labor resource utilization through optimization.

The purpose of this paper is to demonstrate the applicability of the developed material-supply-driven project planning and control scheme in mitigating the negative impact of material delays upon industrial project schedules, specifically in the context of piping spool fabrication. This paper is organized as follows: Literature reviews are conducted first on spool fabrication and module assembly in industrial sector along with potential problems present in the complex supply chain. In the subsequent section, a framework for scheduling piping spool fabrication under the constraints of material supply, contractual deadline, limited labor availability, and technology relationships is proposed. Next, a spool fabrication case study is conducted to demonstrate the effectiveness of the proposed framework in mitigating material delays and achieving the targeted delivery time for a particular spool.

\section{Construction supply chain management}

The construction supply chain is "a network among different stakeholders within a construction project (clients, contractors, suppliers, etc.) that work together in a concerted effort to manage the flow of information, materials, services, products and cash flow" (Xue et al. 2007). It is a concept that was originated and has flourished in the manufacturing industry. However, due to particular characteristics of the construction industry, the supply chain management for the construction industry differs substantially from that for the manufacturing industry. For instance, some construction materials such as concrete are time-sensitive that must be delivered and placed within a certain period. Also, the diversity and uniqueness of construction projects gives rise to different requirements and specifications on material supply and delivery strategies (Morledge et al. 2009). Thus, the just-in-time delivery in the construction domain is still difficult to achieve and may not be realistic in many cases (Dubois and Gadde 2002). Furthermore, each construction project is one-off and engages different suppliers, contractors, and clients. Thus, it is difficult for stakeholders in the construction industry to maintain the long-term, collaborative and mutually beneficial relationships as the stakeholders in the manufacturing industry do (O'Brien et al. 2008). Also, to fully implement the pull-driven supply chain management requires 
the commitment of all stakeholders to make decisions based on the overall project performance instead of their own interest, which is currently hard to achieve in the construction industry. This calls for the rethinking of contractual relations and providing appropriate incentives (Tommelein 1998). All these characteristics make the material supply chain in construction a dynamic process subject to various uncertainties.

As described above, modern construction projects are evolving to resort to modular and off-site prefabrication technologies for better quality and productivity benefits (Construction 2011; Eickmann and Fagerlund 1999). Due to the low labor cost and convenient procurement of basic materials like steel, the engineering and manufacturing for prefabrication components (i.e., pipe spools or steel structure) and modules is usually undertaken by overseas vendors in East Asia, such as South Korea, China (Choi and Song 2014). After the components or modules are manufactured, they will be shipped from the manufacturers in East Asia to the construction sites in North America such as Alberta, Canada. Thus, with more and more prefabricated materials and assemblies, the material supply chain becomes increasingly complicated and uncertain for industrial modular construction projects (Choi and Song 2014; Song et al. 2005). Material supply presents itself as a driver in planning crew installation operations on site, which is aimed to maximize the productivity of skilled labor and heavy equipment, keep schedule extension to the minimum while mitigating project budget overrun.

To more effectively manage construction supply chain, information technology-based material management systems have been developed in research and implemented in practice. Sophisticated sensing technologies such as RFID, GPS, and Wireless Sensor Networks (WSN) have been adopted in construction projects, intended to enhance the visibility of construction materials within the supply chain (Grau et al. 2012; Irizarry et al. 2013). With the application of material management information systems (Jang and Skibniewski 2009; Vaughan et al. 2012) and sensor-based technologies (Taneja et al. 2011), large amounts of high-quality material-related data such as purchase order status, material receipt, and inventory levels become available on a near real-time basis. Therefore, with such material related information, development of a systematic optimization methodology is much desired to derive a plan which optimally allocates limited labor resources in coping with the dynamic supply chain of materials.

\section{The state-of-the-art spool fabrication}

The industrial modular construction is one special type of construction methods commonly adopted in Northern Alberta for oil and gas projects (Taghaddos et al. 2012).
Modularization can reduce the construction cost and duration; also materialize quality and safety objectives under inclement weather conditions and tight labor availability constraints. Spool fabrication is an early process of one industrial construction project and is crucial to the success of entire project delivery (Wang et al. 2009). Prefabrication generally takes place at a specified facility (e.g., fabrication shop), where various materials are conjoined as per the engineering design in order to form a component part of a larger item. Any component that is fabricated off-site and is not a complete system in function can be considered to be pre-fabricated (Taghaddos et al. 2012).

In the spool fabrication shop, a large amount of raw pipe and pipe fittings (e.g., elbow, tee, flanges) are fabricated into pipe spools through a series of operations such as cutting, fitting, welding, quality control checking, stress relief, hydro testing, painting and other surface finishing. The typical fabrication process of one pipe spool is illustrated in Fig. 2. After the engineering drawings are received and all required materials are available, cutting sheets will be released to the fabrication shop. Pipe, as the main component of spools, will first be cut to the desired length and the end surfaces of the pipe are beveled to the specification in the drawings. Then, the pipe sections and pipe fittings are fitted and welded. The fabricated subassembly often needs to be

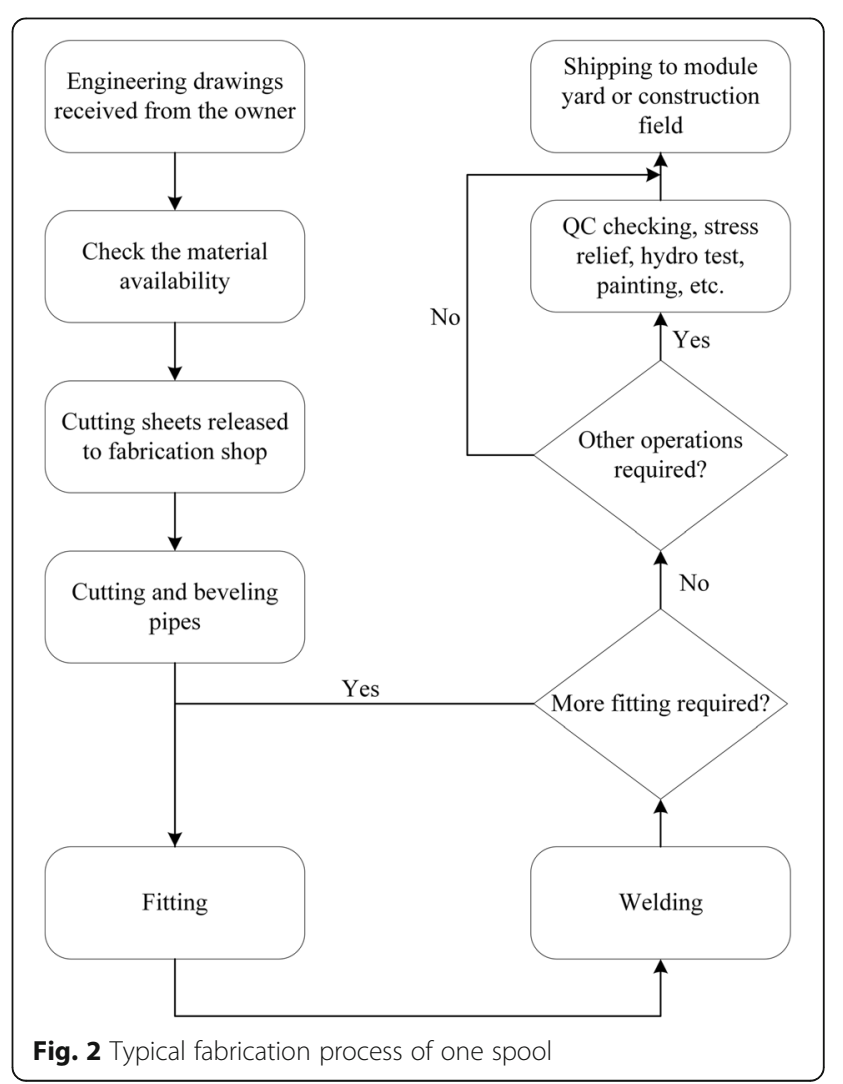


Table 1 Activities involved in fabricating the sample spool

\begin{tabular}{lll}
\hline Activity ID & Activity name & Labor \\
\hline$A_{1}$ & Fit 2 "elbow and 2" flange & Fitter \\
$B_{1}$ & Weld 2 "elbow and 2" flange (sub1_1) & Welder \\
$C_{1}$ & Fit the sub1_1 with 2 "pipe & Fitter \\
$D_{1}$ & Weld the subassembly with 2 "pipe (sub1_2) & Welder \\
$\mathrm{E}_{1}$ & Fit sub1_2 with olet & Fitter \\
$\mathrm{F}_{1}$ & Weld sub1_2 with olet (sub1_3) & Welder \\
$\mathrm{G}_{1}$ & Fit two 6 "pipes together & Fitter \\
$\mathrm{H}_{1}$ & Weld two 6 "pipes together (sub1_4) & Welder \\
$\mathrm{I}_{1}$ & Fit sub1_3 and sub1_4 & Fitter \\
$\mathrm{J}_{1}$ & Weld sub1_3 and sub1_4 & Welder \\
\hline
\end{tabular}

fitted and welded several times on the shop floor before the spool is completed. After that, the spools are checked for quality control, and stress relief, hydro test, painting or other surface finishing work are performed, if required.

As shown in Fig. 2, design drawings provided by owners or engineering companies are the basis to perform work breakdown and activity sequencing. The isometric (ISO) drawing represents the details of the $3 \mathrm{D}$ structure of the pipe in the form of a 2D diagram. Figure 3 shows the isometric (ISO) drawing of one sample spool. It shows the required materials, including material types and quantities; and all welding points for assembling the pipe spool. All the materials are marked with capital letters in an oval shape. Each welding point is indicated by one number with the rectangular box. Note, pipe size is specified with two non-dimensional numbers, namely: a nominal pipe size (NPS) and Schedule (Sch.). NPS is a North American standard for representing the pipe diameter based on inches. "Sch." numbering is a North American standard that denotes the wall thickness of a pipe or pipe fitting, such as Sch. 10, Sch. 40, Sch. 60, Sch. 80, standard wall (STD), extra strong (XS) and double extra strong (XXS).
Higher schedules mean thicker walls of pipe that can resist higher pressures.

The fabrication activities resulting from performing work breakdown are listed in Table 1. The corresponding Activity-On-Node (AON) network illustrating the sequences among different fabrication activities is presented in Fig. 4. Due to the scarcity of experienced fitters and welders, high trades' hourly rates, plus limited spaces on the shop floor for performing fitting and welding, the operations of fitting and welding are two main fabrication operations which need to be meticulously planned. Therefore, in this paper, only the activities related to fitting and welding are considered in scheduling the fabrication of one pipe spool.

The typical real-world scenario is that multiple pipe spools are fabricated simultaneously in one shop, sharing the same labor resources and drawing from the same inventory for most raw materials. And every spool has an expected delivery date to the module yard or to the construction site. As shown above, various types of raw materials (e.g., pipe sections of different sizes, elbows, olets and flanges) are connected in the spool fabrication process. Timely supply of all materials is critical to achieve the smooth execution of the fabrication process. Any delay in material supply processes would postpone start time on corresponding activities, potentially extending the project duration.

However, in the current practice, raw materials are stored in the open area outside the fabrication shop. Although different types of materials are intended to be stored in their predefined areas and classified by using color tapes, they can be moved to other storage areas during retrieval of nearby items (Caldas et al. 2006), which would increase the difficulty of locating raw materials. Also, most raw materials for fabricating pipe spools are bulky and heavy. Equipment (i.e., crane) is required for handling them. Storing raw materials much sooner than needed would result in double-handling waste,

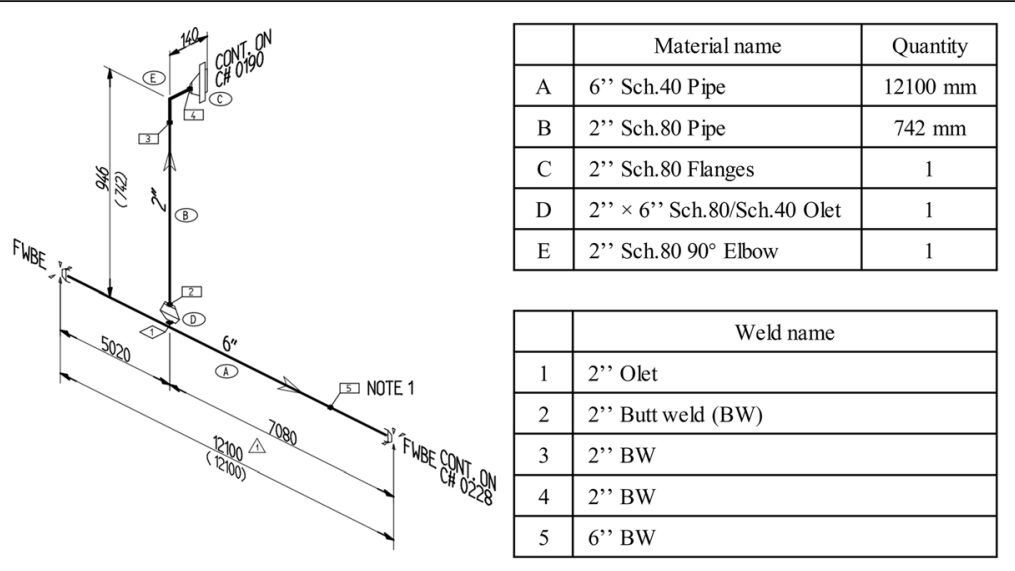

Fig. 3 ISO drawing of one sample spool 


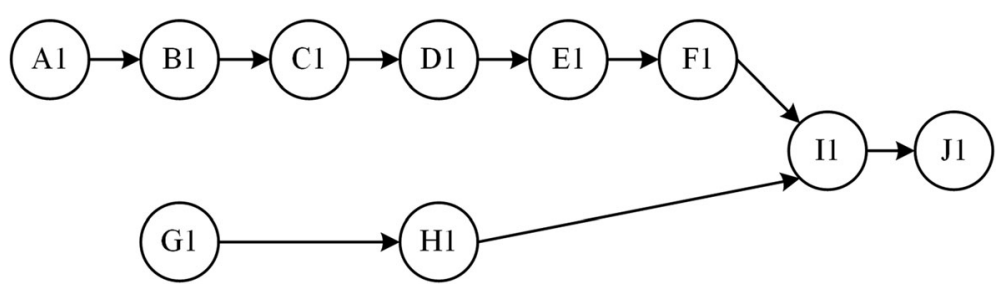

Fig. $4 \mathrm{AON}$ network for fabricating the sample spool

thereby increasing the effort and reducing the efficiency in material management (Ballard and Arbulu 2004). So, the fabricator tends to procure required raw materials based on the actual demand of fabrication in line with the "pull" principle in lean manufacturing. Nonetheless, this would unavoidably give rise to tardy material delivery due to uncertainties along the material supply chain.

Another reason accounting for temporary material shortage in the spool fabrication practice is attributed to the fact that raw materials can be misused in fabrication of spools. For example, a 12-meter-long piece and two 6-meter-long pieces of pipe of the same size, thickness and material type are procured to fabricate Spools A and B. Note the two 6-meter-long pieces of raw pipe are intended for fabricating the two 5-meter-long pipe runs on Spool A. However, in the fabrication process, the 12-meter-long piece of raw pipe is cut into the two 5 -meter-long pipe runs. This happens to cause material storage in fabricating the 10-meter-long pipe section on Spool B, which actually requires the 12-meter-long piece of raw pipe.

Therefore, in the planning of an industrial modular construction project, material availability and material use need to be taken as extra constraints in addition to limited labor resources and fabrication sequences. The resulting fabrication plan will be not only practically relevant to planning fabrication operations and resources, but also instrumental in guiding crews in handling materials with efficiency and delivering fabricated spools under budget.

\section{Methods}

In this study, a generic approach for material-supplydriven project planning and control optimization is adapted into an application framework for scheduling the spool fabrication operations. Figure 5 shows the framework for implementing the developed methodology in scheduling the spool fabrication, which consists of four steps: data sources, extracted information, optimization engine and outputs for decision-support.

As one data source, ISO drawings provide the basis for performing work breakdown and defining all the fabrication activities. The technology-constrained relationships among all activities are also specified in order to properly sequence the execution of activities. In addition, the material supply information extracted from the material management system presents additional constraints. The availability of laborer resources and the preset deadline by which to complete a particular spool project are two other constraints. All these constraints are factored in mathematical programming formulation and entered into the optimization engine in search of the optimum solutions. The mathematical model underlying the proposed framework is shown in Eq. (1).

$$
\min \left(W H_{\text {paid }}\right)=\min (D \times R) ;
$$

subject to:

$$
\begin{aligned}
& \text { (Network Logic Constraint) : } \quad S S_{i} \geq S S_{p}+D_{p}, \quad i=1, \cdots, n_{-} p \\
& \text { (Resource Constraint) : } \sum_{i \in A c_{t}} R_{i, j} \leq R_{j}, \quad t=1, \cdots, D, j=1, \cdots, J \\
& \text { (Deadline Constraint) : } \max _{i \_ \text {spool } \_k}\left\{S S_{i \_ \text {spool } \_k}+D_{i \_ \text {spool_k }}\right\} \leq \text { Dealine } \\
& i \_s p o o l \_k, i \_s p o o l \_k=1, \cdots, n \_s p o o l \_k \\
& \text { (Material Constraint) : } \sum_{i \in A c t_{t}^{\prime}} \text { matl }_{i, c} \leq \text { Matl }_{c}^{t}, \quad c=1, \cdots, C \text {; } \\
& t=1, \cdots, D
\end{aligned}
$$

Where $W_{\text {paid }}$ is the total number of paid worker-hours $(\mathrm{WH}) ; D$ is the total project duration; $R$ is the total number of available labor resources. $S S_{i}$ is the scheduled start time of activity $i . S S_{p}$ and $D_{p}$ are the scheduled start time and duration of the immediate predecessor of activity $i$; $n \_p$ is the total number of its immediate predecessors. $A c t_{t}$ is the set of activities which are in process (already started but not finished), or ready to be started at time $t$; $R_{i, j}$ is the amount of required resource $j$ for activity $i$; $\mathrm{J}$ is the total number of resource types. $n_{-}$spool $k$ is the total number of activities for fabricating spool $k$; Dealine spool_k $_{k}$ is the preset deadline for spool k; the total duration for fabrication spool $k$ is determined by the latest finish time of activities of spool $k$. Act $t_{t}^{\prime}$ is the set of activities which are finished, in process, or ready to be started at time $t$, matl $l_{i, c}$ is the required amount of material $c$ for activity $i$. Mat $l_{c}^{t}$ is the cumulative supply amount of material $c$ at time period $t$. $C$ is the total number of material types.

The mathematical model can be readily solved by using constraint programming engine software, which 


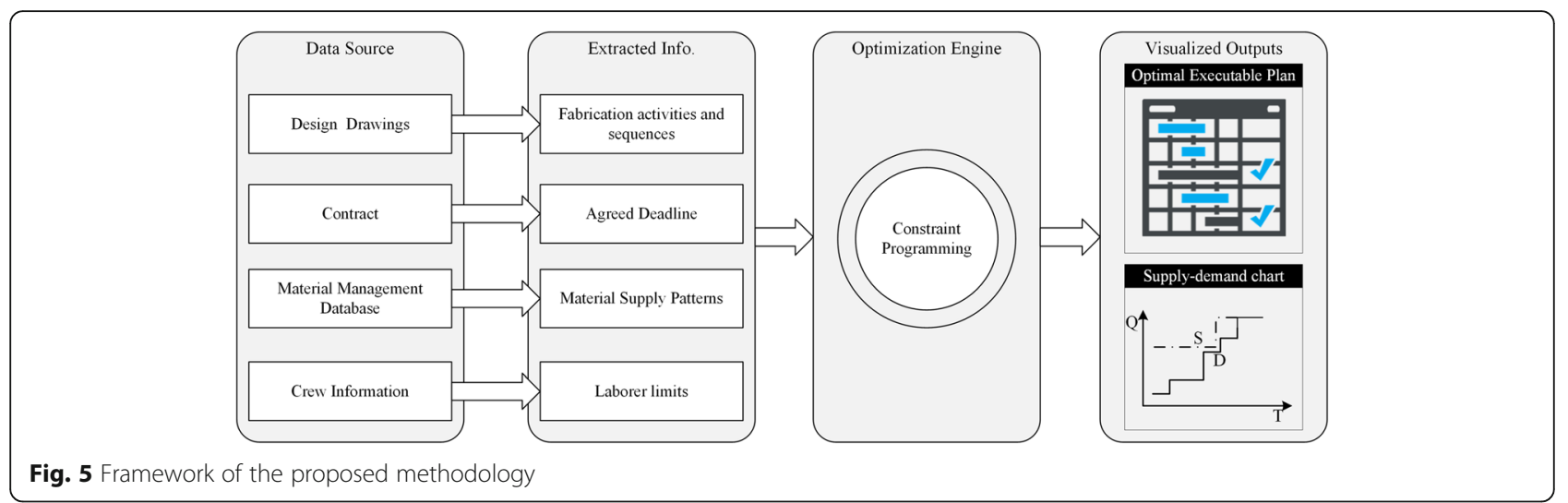

has been proved to be very powerful in industrial control applications (Fromherz et al. 1999). The constraint programming engine software integrates multiple techniques in operations research (OR), artificial intelligence (AI) and graph theory (Rossi et al. 2006) for solving complicated scheduling problems with efficiency and cost-effectiveness (Bockmayr and Hooker 2003). Constraint programming has also been employed in addressing construction scheduling problems of practical size and complexity. Liu and Wang (2012) took advantage of constraint programming to enhance the computing efficiency for scheduling linear construction projects with multi-skilled crews. Menesi et al. (2013) demonstrated the capability of constraint programming to handle the time-cost trade-off problem for large-scale projects involving thousands of activities. In this study, IBM ILOG CPLEX Optimization Studio V12.6 (2016) was utilized to implement constraint programming algorithm in search for the optimum solution to the mathematical model.
There are two forms of visualization based on the optimization results. One is the fabrication schedule with the start time and finish time of all activities. The resulting schedule is with the shortest project duration, thus with the least paid $\mathrm{WH}$, as indicated by Eq. (1). The other output is the material supply-demand chart to illustrate the fitness between the material supply pattern and the material demand pattern over time, as illustrated in Fig. 6. The chart shows the cumulative material supply pattern and material demand pattern over time. The material supply line is derived based on how the material is delivered to the project. A new material arrival at a particular time triggers the "stepping up" event on the material supply line. Similarly, the material demand line is dictated by the project schedule. A start of one activity increases the demand level of the required material. The area between the material supply line and the material demand line indicates the fitness between material supply and material demand. A small value of the

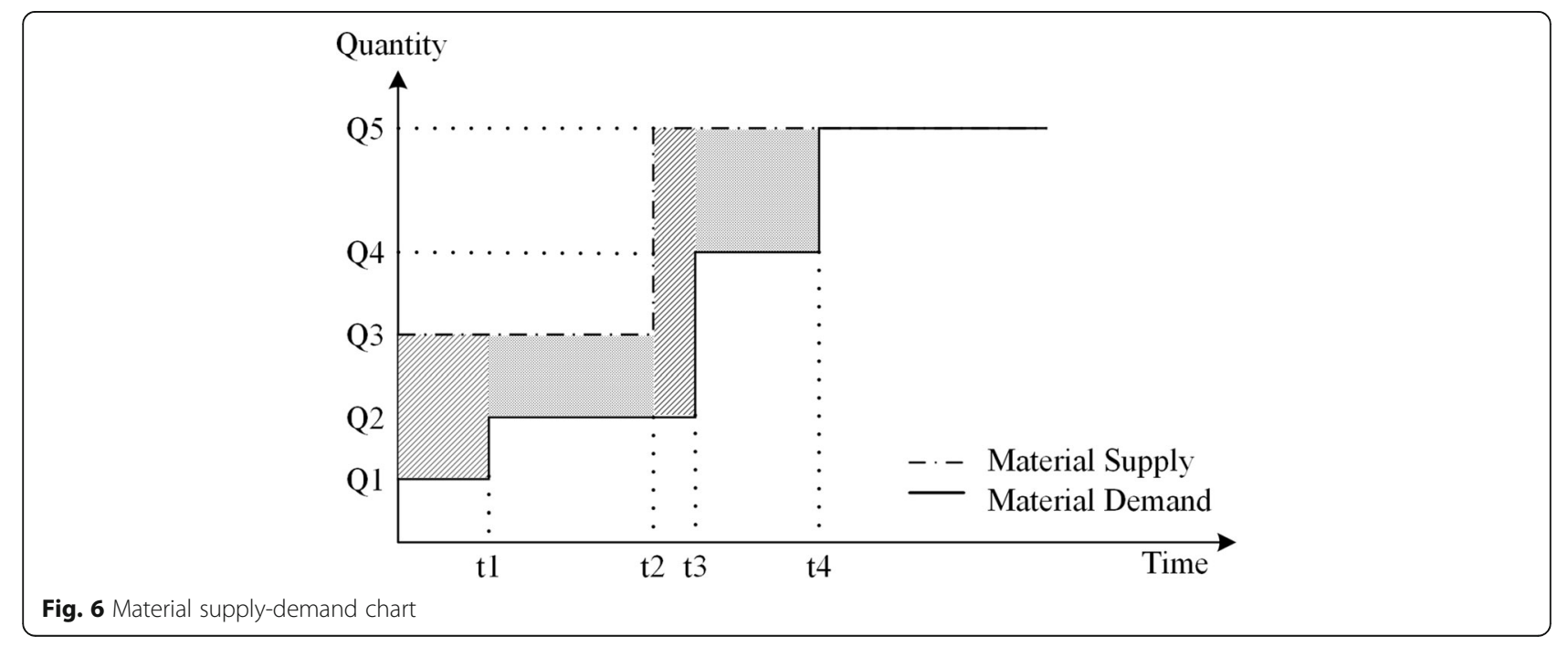




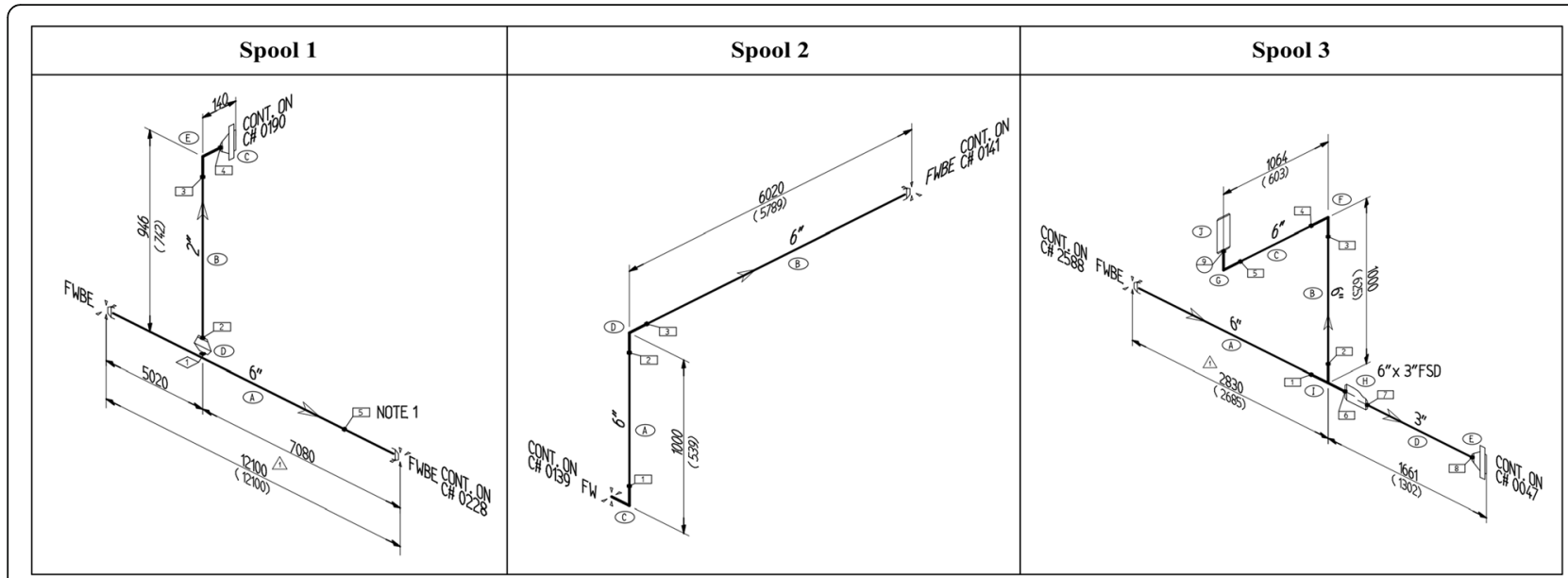

Fig. 7 ISO drawings for three sample spools

area indicates a good match between material supply and material demand. For the material supply-demand chart shown in Fig. 6, the area (greyed) is calculated as Eq. (2):

$$
\begin{aligned}
\text { Area }_{S-D}= & \left(t_{1}-0\right) \times\left(Q_{3}-Q_{1}\right)+\left(t_{2}-t_{1}\right) \\
& \times\left(Q_{3}-Q_{2}\right)+\left(t_{3}-t_{2}\right) \times\left(Q_{5}-Q_{2}\right) \\
& +\left(t_{4}-t_{3}\right) \times\left(Q_{5}-Q_{4}\right)
\end{aligned}
$$

A realistic case study is presented in the following section in order to validate the effectiveness of the proposed application framework for scheduling the spool fabrication based on the project material-supply-driven project planning and control optimization algorithm.

\section{Results and discussion}

The spool fabrication project is part of an oil sands expansion project in Fort McMurray, Alberta. All the spools are pre-fabricated in one fabrication shop located in Edmonton, Alberta. After the spools are finished, they are transported to the module yard or the field by trucks for assembly. In this case study, three sample spools from the project are selected to build a test case, so to verify the feasibility of the proposed framework for scheduling the spool fabrication operations (i.e., mainly fitting and welding) under the constraints of limited laborer resources, preset deadlines of particular spools, technological relationships, and time-dependent material supply patterns. The ISO drawings for the three spools are shown in Fig. 7. All the required materials are listed in Table 2 as well.

The fabrication work breakdown and activity definition were first developed as per the provided ISO drawings of respective spools. After consulting with experienced shop foremen, the activities required for fabricating Spool 1,
Spool 2 and Spool 3 were defined and are tabulated in Table 3 (a), (b) and (c) respectively. The labor requirements and the duration of each activity are listed in Table 3 as well. With the assistance of the fabrication shop staff of the partner company, activity times were obtained in minutes from actual job costing records. The material information for fabricating each spool is listed in Table 4 showing required quantities along with the corresponding activity ID. The logical relationships (i.e., technological constraints) between activities in connection with fabricating each spool are represented in the AON network shown in Fig. 8, which closely mirrors the actual work sequences executed in the fabrication shop of the partner company.

The three spools are different in design, but share the same labor resources (i.e., two fitters and one welder), the same workstations in the shop and draw on the same

Table 2 Required materials for fabricating the three sample spools

\begin{tabular}{ll}
\hline Material name & Quantity \\
\hline 6", Sch.40 Pipe & 23 meter \\
2", Sch.80 Pipe & 1 meter \\
3", Sch.40 Pipe & 1.3 meter \\
2", Sch.80 Elbow & 1 \\
6", Sch.40 Elbow & 4 \\
2", Sch.80 Flange & 1 \\
3", Sch.40 Flange & 1 \\
2" $\times 6 "$, Sch.80/Sch.40 Olet & 1 \\
6" Hydro pipe & 1 \\
$6 " \times 3 "$, Sch.40 Reducer & 1 \\
$6 "$, Sch.40 Tee & 1 \\
\hline
\end{tabular}


Table 3 Activities for fabricating the three sample spools

\begin{tabular}{|c|c|c|}
\hline Activity ID & Activity name & Labor \\
\hline \multicolumn{3}{|c|}{ (a). fabrication activities for Spool 1} \\
\hline$A_{1}$ & Fit 2" elbow and 2" flange & 2 Fitters \\
\hline $\mathrm{B}_{1}$ & Weld 2" elbow and 2" flange (sub1_1) & 1 Welder \\
\hline$C_{1}$ & Fit the sub1_1 with 2" pipe & 2 Fitters \\
\hline$D_{1}$ & $\begin{array}{l}\text { Weld the subassembly with 2" pipe } \\
\text { (sub1_2) }\end{array}$ & 1 Welder \\
\hline$E_{1}$ & Fit sub1_2 with olet & 2 Fitters \\
\hline$F_{1}$ & Weld sub1_2 with olet (sub1_3) & 1 Welder \\
\hline $\mathrm{G}_{1}$ & Fit two 6" pipes together & 2 Fitters \\
\hline $\mathrm{H}_{1}$ & Weld two 6" pipes together (sub1_4) & 1 Welder \\
\hline$I_{1}$ & Fit sub1_3 and sub1_4 & 2 Fitters \\
\hline$J_{1}$ & Weld sub1_3 and sub1_4 & 1 Welder \\
\hline
\end{tabular}

(b). fabrication activities for Spool 2

$\begin{array}{llll}A_{2} & \text { Fit 6" elbow with 6" pipe } & 2 \text { Fitters } & 41 \\ B_{2} & \text { Weld 6" elbow with 6" pipe (sub2_1) } & 1 \text { Welder } & 68 \\ C_{2} & \text { Fit sub2_1 with 6" pipe } & 2 \text { Fitters } & 39 \\ D_{2} & \text { Weld sub2_1 with 6" pipe } & 1 \text { Welder } & 69\end{array}$

(c). fabrication activities for Spool 3

\begin{tabular}{|c|c|c|c|}
\hline$A_{3}$ & Fit 6" hydro pipe and 6" elbow & 2 Fitters & 12 \\
\hline $\mathrm{B}_{3}$ & $\begin{array}{l}\text { Weld 6" hydro pipe and 6" elbow } \\
\text { (sub3_1) }\end{array}$ & 1 Welder & 42 \\
\hline$C_{3}$ & Fit 6" elbow and 6" pipe & 2 Fitters & 15 \\
\hline$D_{3}$ & Weld 6" elbow and 6" pipe (sub3_2) & 1 Welder & 14 \\
\hline$E_{3}$ & Fit sub3_1 and sub3_2 & 2 Fitters & 18 \\
\hline$F_{3}$ & Weld sub3_1 and sub3_2 (sub3_3) & 1 Welder & 12 \\
\hline $\mathrm{G}_{3}$ & Fit 6" pipe and tee & 2 Fitters & 31 \\
\hline $\mathrm{H}_{3}$ & Weld 6" pipe and tee (sub3_4) & 1 Welder & 56 \\
\hline$I_{3}$ & Fit sub3_4 and reducer & 2 Fitters & 37 \\
\hline$J_{3}$ & Weld sub3_4 and reducer (sub3_5) & 1 Welder & 46 \\
\hline $\mathrm{K}_{3}$ & Fit sub3_5 and 3" pipe & 2 Fitters & 19 \\
\hline $\mathrm{L}_{3}$ & Weld sub3_5 and 3" pipe (sub3_6) & 1 Welder & 15 \\
\hline$M_{3}$ & Fit sub3_6 and 3" Flange & 2 Fitters & 11 \\
\hline $\mathrm{N}_{3}$ & Weld sub3_6 and 3" Flange (sub3_7) & 1 Welder & 130 \\
\hline $\mathrm{O}_{3}$ & Fit sub3_3 and 6" pipe & 2 Fitters & 27 \\
\hline$P_{3}$ & Weld sub3_3 and 6" pipe (sub3_8) & 1 Welder & 52 \\
\hline $\mathrm{Q}_{3}$ & Fit sub3_7 and sub3_8 & 2 Fitters & 29 \\
\hline$R_{3}$ & Weld sub3_7 and sub3_8 & 1 Welder & 80 \\
\hline
\end{tabular}

inventory of raw materials (i.e., raw pipe and pipe fittings). The proposed optimization approach is used to schedule the fabrication of the three spools in order to finish them in the shortest duration with the fixed labor resources (two fitters and one welder allocated); in the meantime, the material demand pattern dictated by the
Table 4 Materials for fabricating the three sample spools

\begin{tabular}{|c|c|c|c|}
\hline \multirow[t]{2}{*}{ Activity ID } & \multirow[t]{2}{*}{ Activity name } & \multicolumn{2}{|l|}{ Required material } \\
\hline & & Name & Quantity \\
\hline \multirow[t]{2}{*}{$A_{1}$} & \multirow[t]{2}{*}{ Fit 2" elbow and 2" flange } & 2" elbow & 1 \\
\hline & & 2" Flange & 1 \\
\hline$C_{1}$ & Fit the sub1_1 with 2" pipe & 2" pipe & 1 meter \\
\hline$E_{1}$ & Fit sub1_2 with olet & Olet & 1 \\
\hline $\mathrm{G}_{1}$ & Fit two 6" pipes together & 6" pipe & 12.1meter \\
\hline \multirow[t]{2}{*}{$A_{2}$} & \multirow[t]{2}{*}{ Fit 6" elbow with 6" pipe } & 6" elbow & 2 \\
\hline & & 6" pipe & 0.6 meter \\
\hline $\mathrm{C}_{2}$ & Fit sub2_1 with 6" pipe & 6" pipe & 5.8 meter \\
\hline \multirow[t]{2}{*}{$A_{3}$} & \multirow[t]{2}{*}{ Fit 6" hydro pipe and 6" elbow } & 6" hydro pipe & 1 \\
\hline & & 6" elbow & 1 \\
\hline \multirow[t]{2}{*}{$C_{3}$} & \multirow[t]{2}{*}{ Fit 6" elbow and 6" pipe } & 6" elbow & 1 \\
\hline & & 6" pipe & 0.6 meter \\
\hline \multirow[t]{2}{*}{$\mathrm{G}_{3}$} & \multirow[t]{2}{*}{ Fit 6" pipe and tee } & 6" pipe & 2.7 meter \\
\hline & & Tee & 1 \\
\hline$I_{3}$ & Fit sub3_4 and reducer & $6 " \times 3^{\prime \prime}$ reducer & 1 \\
\hline $\mathrm{K}_{3}$ & Fit sub3_5 and 3" pipe & 3" pipe & 1.3 meter \\
\hline$M_{3}$ & Fit sub3_6 and 3" Flange & 3" Flange & 1 \\
\hline $\mathrm{O}_{3}$ & Fit sub3_3 and 6" pipe & 6" pipe & 0.6 meter \\
\hline
\end{tabular}

schedule must match the time-dependent material supply pattern. Note the unit of time for scheduling anlysis is minute $(\mathrm{min})$ in order to be in line with the activity time available. As required by the contract, Spool 3 needs to be finished on Day 2, i.e., the $960^{\text {th }}$ minutes after project starts (assume 8 working hours per day). Figure 9 shows the Gantt chart of the baseline schedule with the assumption that all materials are available when needed. It is worth mentioning that the output visulization is designed to be intuitive to users and also interactive with users. When the mouse cursor moves on activities, the detailed information of corresponding activities including spool identification, activity identification, duration, start time and required resources pops up as shown in Fig. 10, which makes the Gantt chart much easier to communicate, comprehend and execute by practitioners. As indicated by the baseline schedule, the three spools can be completed with $774 \mathrm{~min}$, which is roughly $13 \mathrm{~h}$ with two fitters and one welder. And Spool 3 is completed at the $774^{\text {th }}$ minute, which is less than the deadline of $960 \mathrm{~min}$.

The material demand pattern based on the baseline schedule and the prescheduled material supply pattern for each material are shown in Table 5. It is observed that the material supply can satisfy the demand of the baseline schedule. Figure 11 presents the time-dependent supply- 


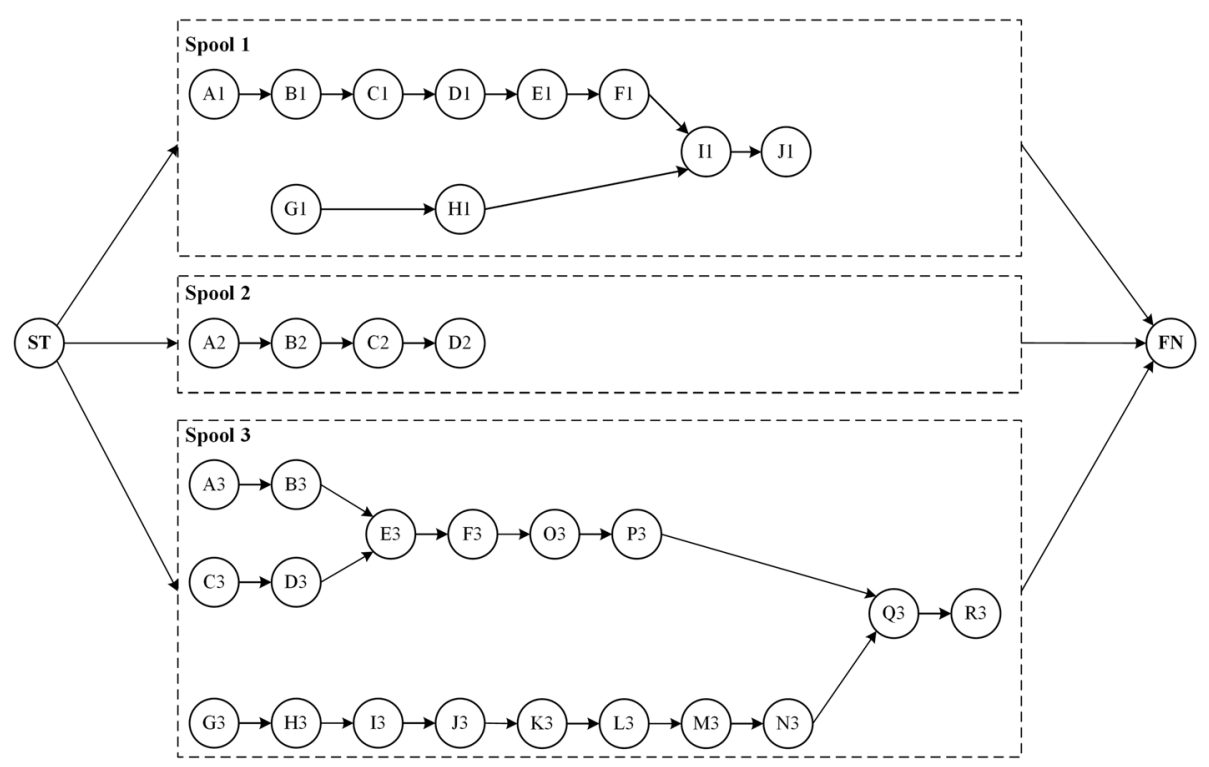

Fig. 8 AON network for fabricating the three sample spools

demand visualization for 6", Sch.40 pipe. The area between the supply line and the demand line is 2316 (meter $\bullet$ min.)

However, before starting the fabrication of the three sample spools, the shop foreman is notified that the supplies of $6 "$, Sch.40 pipe and $6 " \times 3 "$, Sch.40 reducer are delayed to the $600^{\text {th }}$ minute from the original time at the $120^{\text {th }}$ minute. Thus, the baseline schedule cannot be executed as planned. To mitigate the impact of material delay on schedule performance,

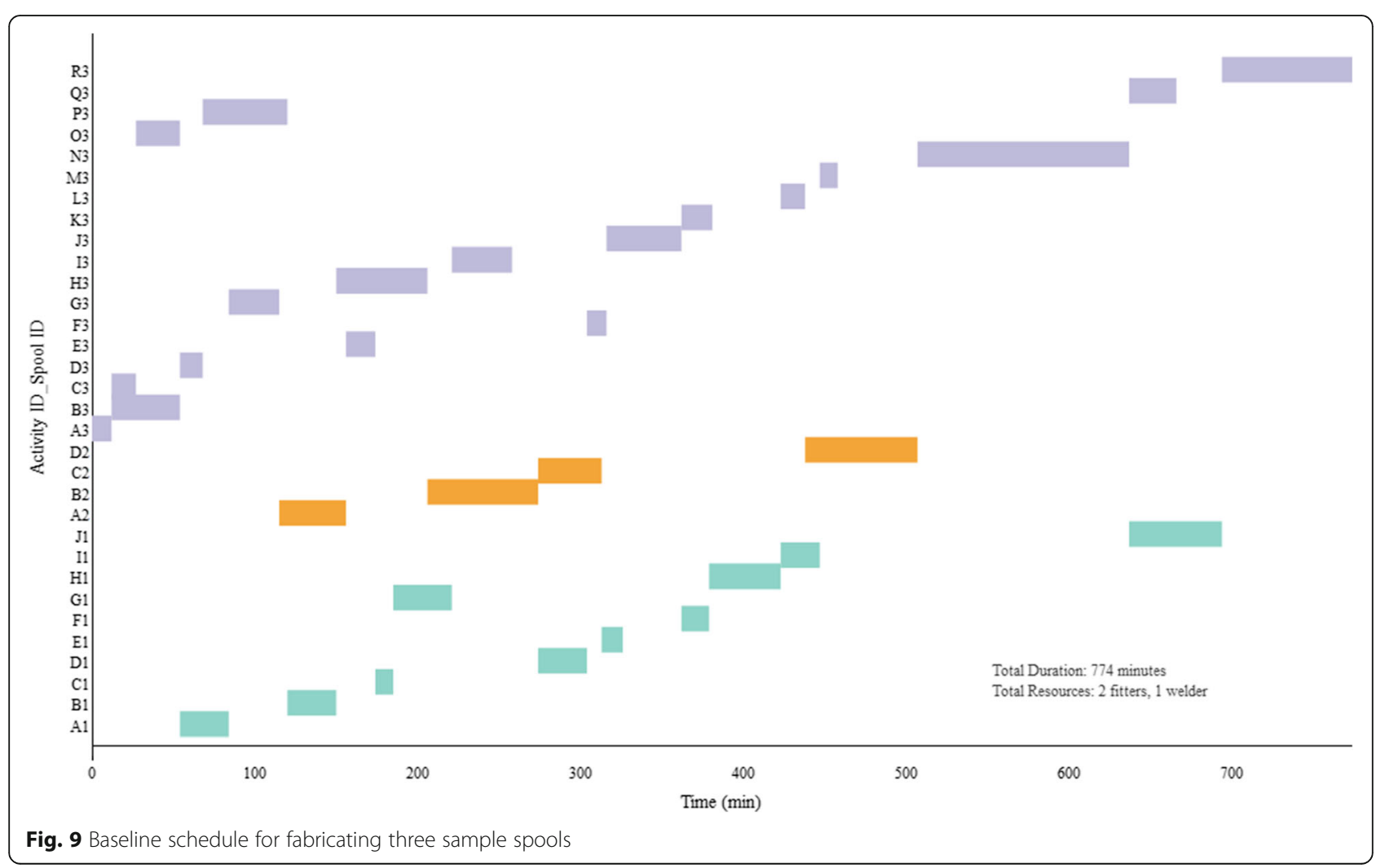




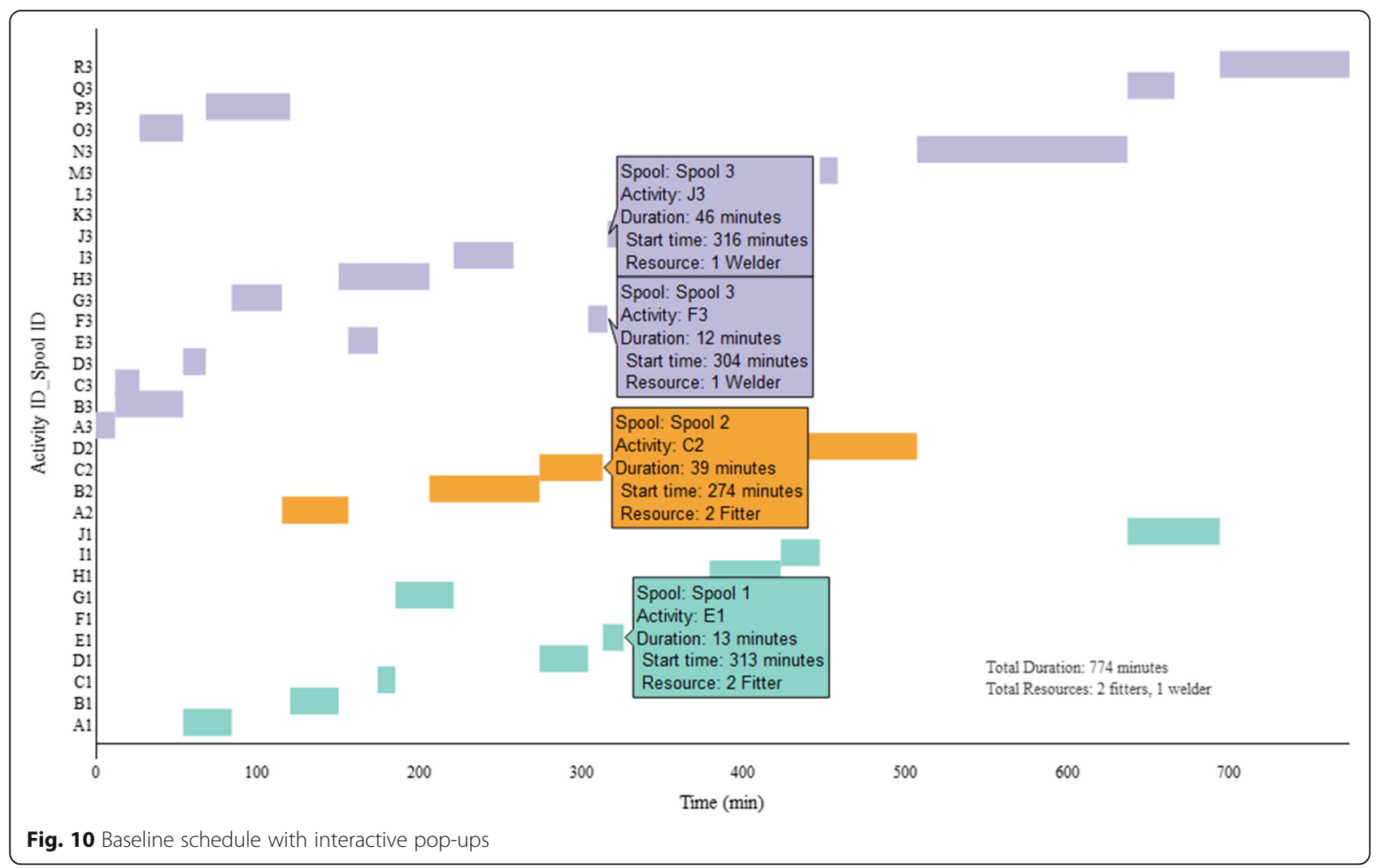

Table 5 Cumulative supply and cumulative demand of all materials

\begin{tabular}{|c|c|c|c|c|c|c|c|c|c|c|c|c|}
\hline \multirow[t]{2}{*}{ Material name } & \multicolumn{2}{|c|}{ 6", Sch.40 Pipe } & \multicolumn{2}{|c|}{ 2", Sch.80 Pipe } & \multicolumn{2}{|c|}{ 3", Sch.40 Pipe } & \multicolumn{2}{|c|}{ 2", Sch.80 Elbow } & \multicolumn{2}{|c|}{ 6", Sch.40 Elbow } & \multicolumn{2}{|c|}{ 2", Sch.80 Flange } \\
\hline & Time & Quantity & Time & Quantity & Time & Quantity & Time & Quantity & Time & Quantity & Time & Quantity \\
\hline \multirow[t]{2}{*}{ Supply } & 0 & 5 & 0 & 1 & 0 & 1.3 & 0 & 1 & 0 & 4 & 0 & 1 \\
\hline & 120 & 22.4 & - & - & - & - & - & - & - & - & - & - \\
\hline \multirow[t]{7}{*}{ Demand } & 0 & 0 & 0 & 0 & 0 & 0 & 0 & 0 & 0 & 1 & 0 & 0 \\
\hline & 12 & 0.6 & 174 & 1 & 362 & 1.3 & 54 & 1 & 12 & 3 & 54 & 1 \\
\hline & 27 & 1.2 & - & - & - & - & - & - & 115 & 4 & - & - \\
\hline & 84 & 3.9 & - & - & - & - & - & - & - & - & - & - \\
\hline & 115 & 4.5 & - & - & - & - & - & - & - & - & - & - \\
\hline & 185 & 16.6 & - & - & - & - & - & - & - & - & - & - \\
\hline & 274 & 22.4 & - & - & - & - & - & - & - & - & - & - \\
\hline \multirow[t]{2}{*}{ Material name } & \multicolumn{2}{|c|}{ 3", Sch.40 Flange } & \multicolumn{2}{|c|}{$2^{\prime \prime} \times 6^{\prime \prime}$, Sch. $80 /$ Sch.40 Olet } & \multicolumn{2}{|c|}{ 6" Hydro pipe } & \multicolumn{2}{|c|}{$6 " \times 3^{\prime \prime}$, Sch.40 Reducer } & \multicolumn{2}{|c|}{ 6", Sch.40 Tee } & & \\
\hline & Time & Quantity & Time & Quantity & Time & Quantity & Time & Quantity & Time & Quantity & & \\
\hline \multirow[t]{2}{*}{ Supply } & 0 & 0 & 0 & 0 & 0 & 1 & 0 & 0 & 0 & 1 & & \\
\hline & 180 & 1 & 180 & 1 & - & - & 120 & 1 & - & - & & \\
\hline \multirow[t]{2}{*}{ Demand } & 0 & 0 & 0 & 0 & 0 & 1 & 0 & 0 & 0 & 0 & & \\
\hline & 447 & 1 & 313 & 1 & & & 221 & 1 & 84 & 1 & & \\
\hline
\end{tabular}




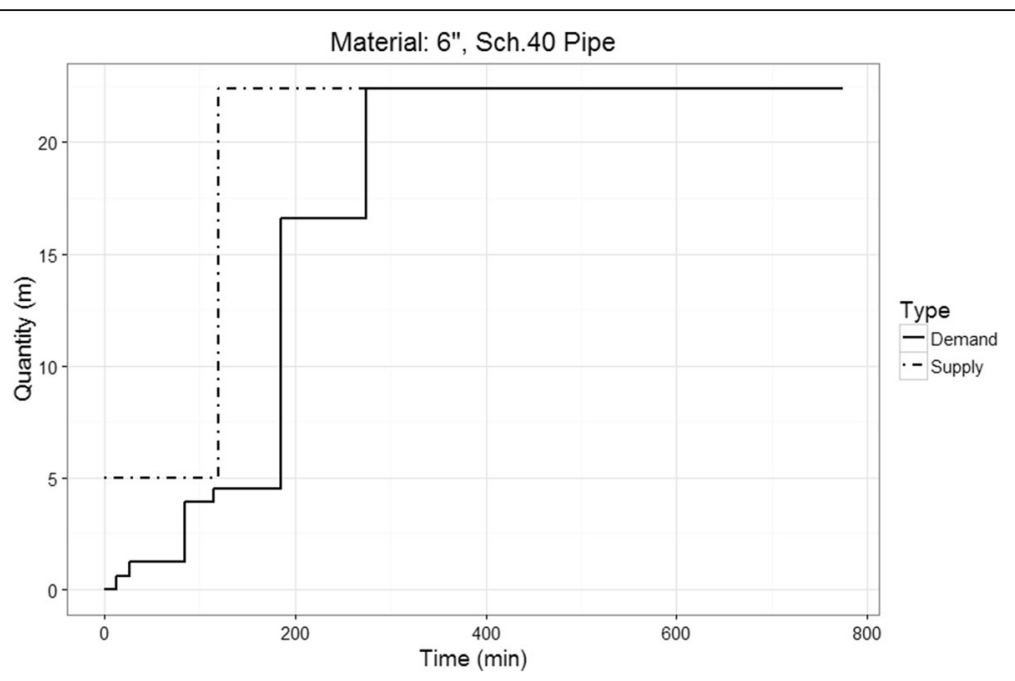

Fig. 11 Supply-demand chart for 6", Sch.40 pipe

the developed optimization algorithm is re-run to generate an alternative schedule under the constraints of updated material supply status. For this scenario, the deadline constraint is removed from the mathematical model shown in Eq. (1), as the deadline constraint of spool 3 cannot be satisfied due to the material delay. The resulting schedule is shown in Fig. 12. The fabrication process is suspended from the $335^{\text {th }}$ minute to the $600^{\text {th }}$ minute, on which point of time the materials are ready in the shop. The updated duration becomes $1078 \mathrm{~min}$ and Spool 3 is finished at the $1078^{\text {th }}$ minute, which is beyond the preset deadline (the $960^{\text {th }}$ minute). The corresponding material

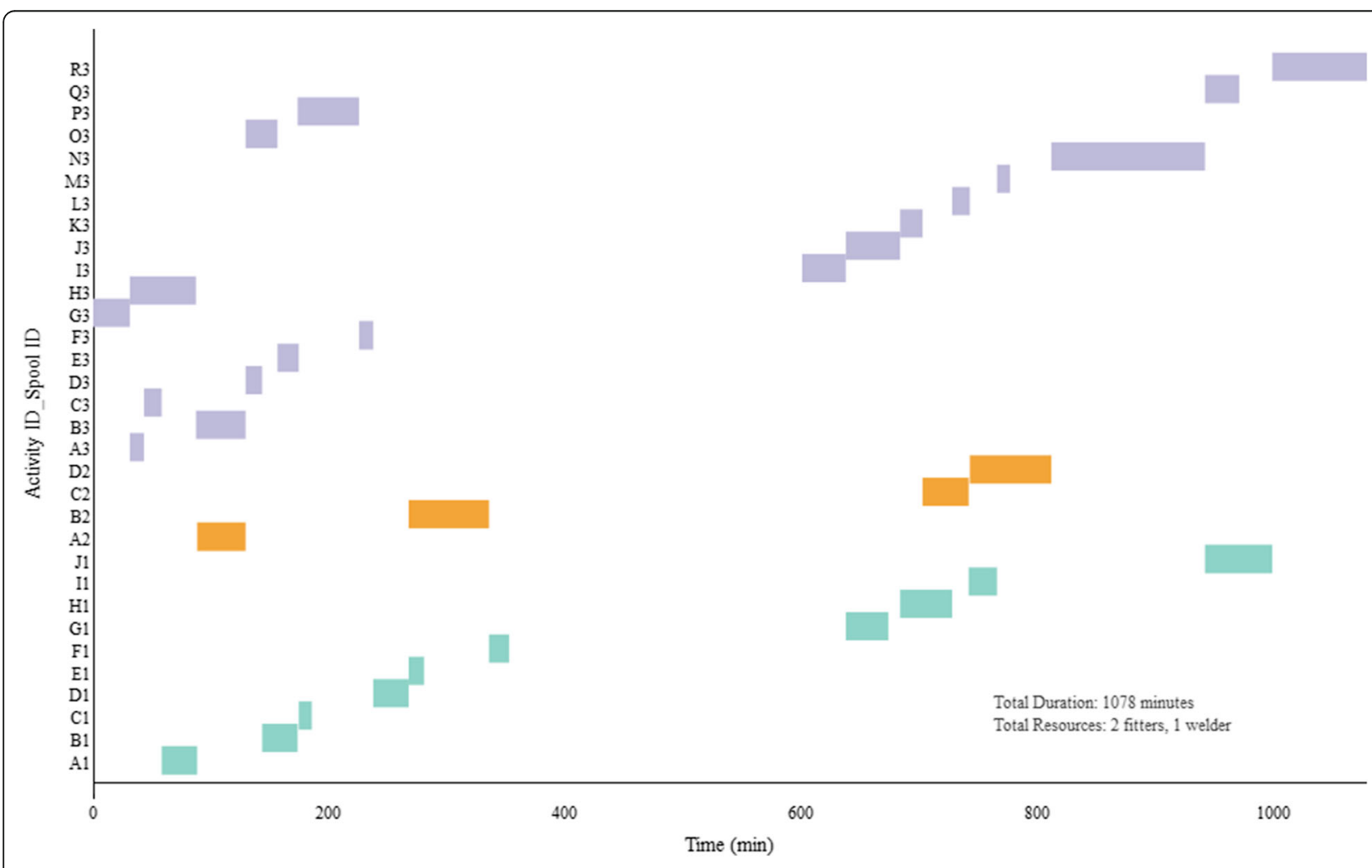

Fig. 12 Updated schedule with the shortest duration 


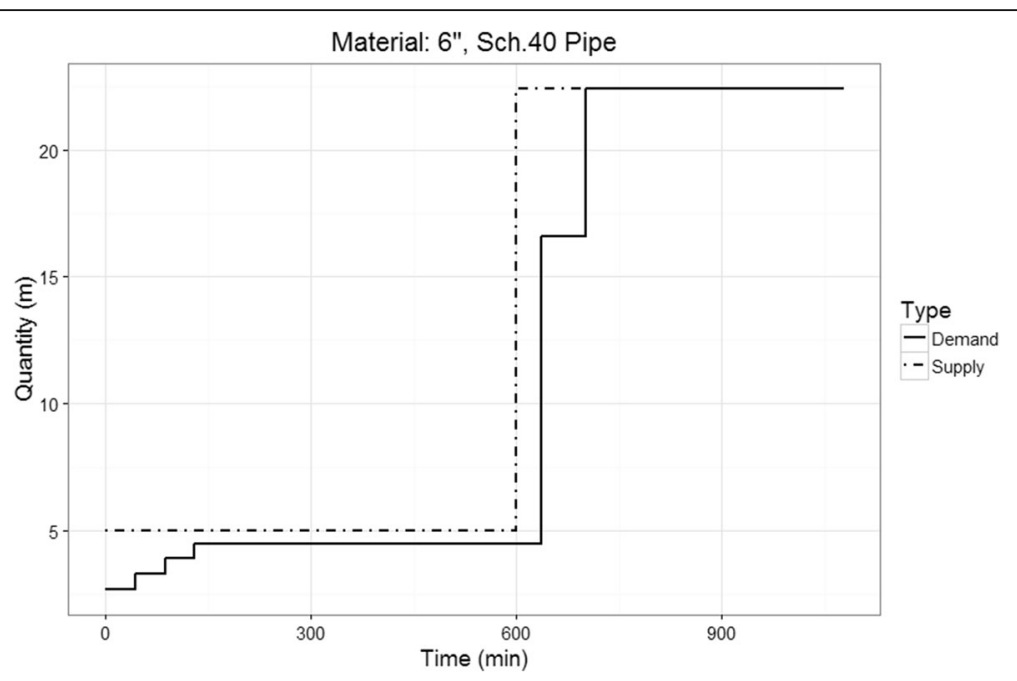

Fig. 13 Supply-demand chart for 6", Sch.40 pipe of the schedule with the shortest duration

supply-demand visualization is updated as shown in Fig. 13. The area between the supply line and the demand line changes to 1495.3 (meter $\bullet$ min.).

In order to finish Spool 3 with the least delay or no delay, the objective function in the mathematical model given in Eq. (1) can be adjusted to minimize the finish time of Spool 3. Thus, the mathematical model is updated to Eq. (3).

$$
\min \left(D_{\text {spool_k }}\right)
$$

where

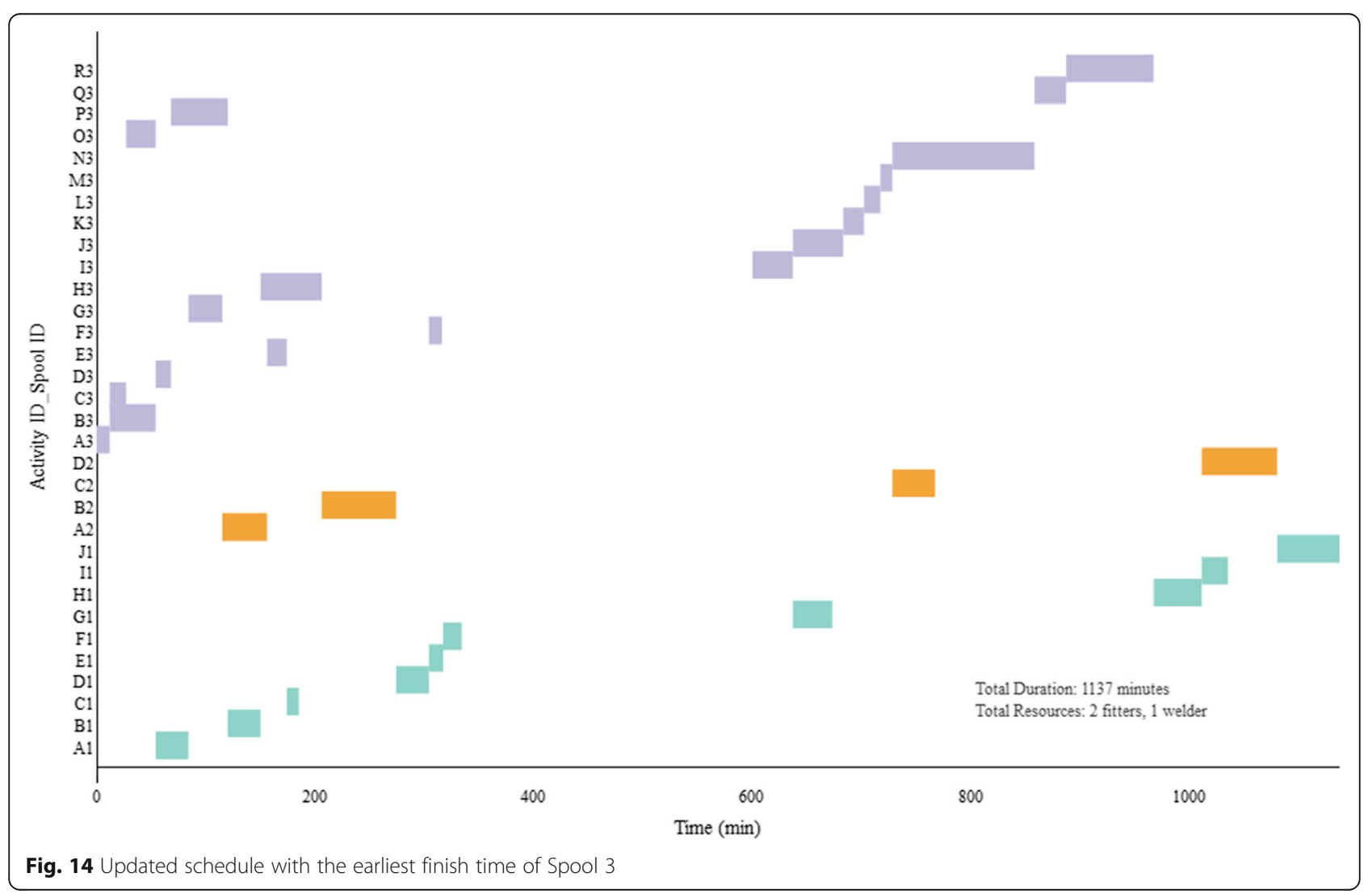




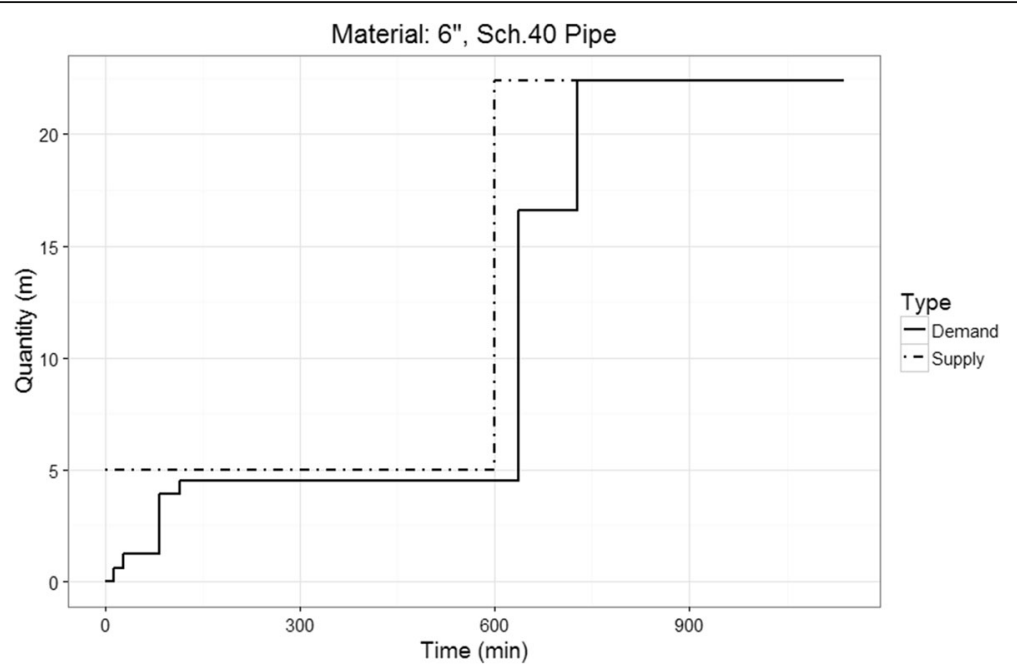

Fig. 15 Supply-demand chart for 6", Sch.40 pipe of the schedule with the earliest finish time of Spool 3

$$
D_{\text {spool_k }}=\max _{i_{\text {spool_k }}}\left\{S S_{i_{-s p o o l \_k}}+D_{i_{-s p o o l \_k}}\right\}
$$

subject to:

$$
\begin{aligned}
& \text { (Network Logic Constraint) : } \quad S S_{i} \geq S S_{p}+D_{p} i=1, \cdots, n_{-} p \\
& \text { (Resource Constraint) : } \sum_{i \in A c t_{t}} R_{i, j} \leq R_{j}, \quad t=1, \cdots, D, j=1, \cdots, J \\
& \text { (Material Constraint) : } \sum_{i \in A c t_{t}^{\prime}} \operatorname{matl}_{i, c} \leq \text { Matl }_{c}^{t}, \quad c=1, \cdots, C ; \\
& t=1, \cdots, D
\end{aligned}
$$

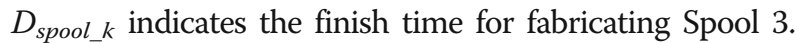
After computer optimization, the resulting schedule is presented in Fig. 14. Similarly, for the schedule, the fabrication process is suspended as well from the $334^{\text {th }}$ minute to the $600^{\text {th }}$ minute. As the updated schedule in Fig. 14 shows, the earliest possible finish time on Spool 3 would be $967 \mathrm{~min}$, which is close to the completion time by the client. As the higher priority is assigned to finishing Spool 3 as early as possible in optimization, the total duration for fabricating the three spools is prolonged to $1137 \mathrm{~min}$. It means the paid worker-hours would increase as well. The material supply-demand chart for pipe with 6" and Sch. 40 is updated as Fig. 15 and the area is of 1809.3 meter $\bullet$ min. between the supply line and the demand line. In short, the two updated schedules provide two alternative strategies for practitioners in managing the material delay with different priorities, which can be the shortest project duration (completing the three spools) or the earliest finish time of particular spool (in response to client request).

To evaluate the effectiveness of the proposed method in solving the scheduling problem, computer execution times on the three scenarios was recorded based on a desktop with a 3.2-GHz CPU and $8 \mathrm{~GB}$ random-access memory (RAM). The computer execution time includes
(1) time to generate the model, (2) time for the engine to solve the model and (3) time to display the results. The model of the case study includes 32 activities, 64 variables and 97 constraints. The execution time averaged over 100 independent runs for each scenario is as follows: $0.0311 \mathrm{~s}$ for generating the baseline schedule, $0.0377 \mathrm{~s}$ for generating the updated schedule with the shortest duration, and $0.0336 \mathrm{~s}$ for generating the updated schedule with the earliest finish time of Spool 3, respectively. The computing performance in optimizing schedules in the case study demonstrates the potential of scaling up the application of the proposed method in coping with material delays and making detailed resource-loaded crew-job schedules in a piping fabrication shop, which generally serves multiple projects and multiple clients simultaneously in real world settings.

\section{Conclusion}

With more and more prefabricated materials and assemblies, the construction material supply chain becomes increasingly complicated and uncertain. Material delay is commonly encountered in spool fabrication shops serving the needs of multiple industrial construction projects. Therefore, this paper proposes an application framework for implementing material-supply driven project planning and control in order to improve the schedule performance of spool fabrication projects subject to time-dependent material supply information collected in material management systems. The application framework consists of four major components, which are (1) data sources, containing detailed design drawings, contract information, resources availability and time-dependent material supply patterns; (2) extracted information serving as constraints for optimizing spool fabrication schedules; (3) constraint programming 
optimization engine; and (4) two forms of output visualization, i.e., the interactive activity Gantt chart and the material supply-demand chart, which guide decisionmaking processes subject to material delays. Three sample spools from a real oil and gas expansion project in Alberta are selected to build a case study for demonstration and validation of the proposed application framework. In addition to the baseline schedule, two alternative schedules with different priorities in defining scheduling optimization objectives, namely, the shortest fabrication duration and the earliest finish time of the particular spool, are produced, lending effective decision support for practitioners in coping with material delays and making detailed resource-loaded crew-job schedules in a piping fabrication shop which generally serves multiple projects and multiple clients simultaneously.

\section{Funding}

This work is substantially funded by National Science and Engineering Research Council (NSERC) and JV Driver Projects Inc. through a Collaborative Research and Development Grant (CRDPJ 414616 - 11).

\section{Authors' contributions}

$J \mathrm{~L}$ carried out literature review, developed and implemented the algorithm, and drafted the manuscript. MS assisted in conducting literature review and collecting project drawings and productivity data in the case study. ML defined the initial problem, supervised the research team in doing the research, advised on paper writing and revision. All authors read and approved the final manuscript.

\section{Competing interests}

The authors declare that they have no competing interests.

\section{Publisher's Note}

Springer Nature remains neutral with regard to jurisdictional claims in published maps and institutional affiliations.

Received: 5 November 2016 Accepted: 29 March 2017 Published online: 11 April 2017

\section{References}

Arbulu, R., \& Ballard, G. (2004). Lean supply systems in construction. Conpenhague: International Group for Lean Construction.

Ballard, G., \& Arbulu, R. (2004). Making prefabrication lean. In Proc. 12th Ann. Conf. of the Int'l. Group for Lean Constr, pp. 3-5.

Bockmayr, A., \& Hooker, J. N. (2003). Constraint programming. In K. Aardal, G. Nemhauser, \& R. Weismantel (Eds.), Handbook of discrete optimization.

Caldas, C. H., Torrent, D. G., \& Haas, C. T. (2006). Using global positioning system to improve materials-locating processes on industrial projects. Journal of Construction Engineering and Management, 132(7), 741-749.

Choi, J., \& Song, H. (2014). Evaluation of the modular method for industrial plant construction projects. International Journal of Construction Management, 14(3), 171-180.

Construction, M. H. (2011). Prefabrication and modularization: increasing productivity in the construction industry. Smart Market Report.

Dubois, A., \& Gadde, L.-E. (2002). The construction industry as a loosely coupled system: implications for productivity and innovation. Construction Management \& Economics, 20(7), 621-631.

Eickmann, JA, and Fagerlund, WR (1999). "Prefabrication and preassembly trends and effects on the construction workforce." University of Texas at Austin.

Fromherz, M. P. J., Saraswat, V. A., \& Bobrow, D. G. (1999). Model-based computing: Developing flexible machine control software. Artificial Intelligence, 114(1), 157-202.

Grau, D., Zeng, L., \& Xiao, Y. (2012). Automatically tracking engineered components through shipping and receiving processes with passive identification technologies. Automation in Construction, 28, 36-44.
Haas, C.T., O'Connor, J.T., Tucker, R.T., Eickmann, J.A., and Fagerlund, W.R. (2000). "Prefabrication and preassembly trends and effects on the construction workforce." Rep. No. 14, Center for Construction Industry Studies, Austin, Texas.

IBM ILOG CPLEX Optimization Studio V12.6. 2016. [Computer software]. Armonk: IBM. https://www.ibm.com/support/knowledgecenter/SSSA5P_12.6.3/ilog. odms.studio.help/Optimization_Studio/topics/COS_relnotes_intro.html.

Irizarry, J., Karan, E. P., \& Jalaei, F. (2013). Integrating BIM and GIS to improve the visual monitoring of construction supply chain management. Automation in Construction, 31, 241-254.

Jang, W.-S., \& Skibniewski, M. J. (2009). Cost-benefit analysis of embedded sensor system for construction materials tracking. Journal of Construction Engineering and Management, 135(5), 378-386.

Koskela, L., Howell, G., Ballard, G. and Tommelein, I. (2002) The foundations of lean construction, in Best, R. and De Valence, G. (eds): Design and Construction: Building in Value, Butterworth-Heinemann, Oxford, pp. 211-226.

Liu, S.-S., \& Wang, C.-J. (2012). Optimizing linear project scheduling with multi-skilled crews. Automation in Construction, 24, 16-23.

Menesi, W., Golzarpoor, B., \& Hegazy, T. (2013). Fast and near-optimum schedule optimization for large-scale projects. Journal of Construction Engineering and Management, 139(9), 1117-1124.

Morledge, R., Knight, A., Grada, M., \& Pryke, S. (2009). The concept and development of supply chain management in the UK construction industry. Construction Supply Chain Management, 3, 23.

O'Brien, W.., Formoso, C., London, K. and Vrijhoef, R. (2008) Construction Supply Chain Management Handbook, CRC Press/Taylor \& Francis, Boca Raton and London.

F. Rossi, P. van Beek, and T. Walsh. (2006) Handbook of Constraint Programming (Foundations of Artificial Intelligence). Elsevier Science Inc., New York, NY, USA.

Song, J., Fagerlund, W. R., Haas, C. T., Tatum, C. B., \& Vanegas, J. A. (2005). Considering prework on industrial projects. Journal of Construction Engineering and Management, 131(6), 723-733.

Song, L., Mohamed, Y., \& AbouRizk, S. M. (2009). Early contractor involvement in design and its impact on construction schedule performance. Journal of Management in Engineering, 25(1), 12-20.

Statistics Canada. (2016a). Employment by industry. http://www.statcan.gc.ca/ tables-tableaux/sum-som/l01/cst01/econ40-eng.htm.

Statistics Canada. (2016b). Gross domestic product at basic prices, construction and manufacturing industries. http://www.statcan.gc.ca/tables-tableaux/sum-som/ 101/cst01/manuf10-eng.htm.

Taghaddos, H., Hermann, U., AbouRizk, S., \& Mohamed, Y. (2012). Simulationbased multiagent approach for scheduling modular construction. Journal of Computing in Civil Engineering, 28(2), 263-274.

Taneja, S., Akinci, B., Garrett, J., Soibelman, L., Ergen, E., Pradhan, A., Tang, P., Berges, M., Atasoy, G., Liu, X., Shahandashti, S., \& Anil, E. (2011). Sensing and field data capture for construction and facility operations. Journal of Construction Engineering and Management, 137(10), 870-881.

Thomas, H. R., \& Sanvido, V. E. (2000). Role of the fabricator in labor productivity. Journal of Construction Engineering and Management, 126(5), 358-365.

Tommelein, I. D. (1998). Pull-driven scheduling for pipe-spool installation: Simulation of lean construction technique. Journal of Construction Engineering and Management, 124(4), 279-288.

Tommelein, I. D., Walsh, K. D., \& Hershauer, J. C. (2003). Capital projects supply chain management. Austin: Construction Industry Institue (CII).

Tserng, H. P., Yin, S. Y., \& Li, S. (2006). Developing a resource supply chain planning system for construction projects. Journal of Construction Engineering and Management, 132(4), 393-407.

Vaughan, J. L., Leming, M. L., Liu, M., \& Jaselskis, E. (2012). Cost-benefit analysis of construction information management system implementation: case study. Journal of Construction Engineering and Management, 139(4), 445-455.

Walsh, K. D., Hershauer, J. C., Tommelein, I. D., \& Walsh, T. A. (2004). Strategic positioning of inventory to match demand in a capital projects supply chain. Journal of Construction Engineering and Management, 130(6), 818-826.

Wang, P., Mohamed, Y., Abourizk, S., \& Rawa, A. (2009). Flow production of pipe spool fabrication: simulation to support implementation of lean technique. Journal of Construction Engineering and Management, 135(10), 1027-1038.

Xu, X., Zhao, Y., \& Chen, C. Y. (2016). Project-driven supply chains: integrating safety-stock and crashing decisions for recurrent projects. Annals of Operations Research, 241(1-2), 225-247.

Xue, X., Wang, Y., Shen, Q., \& Yu, X. (2007). Coordination mechanisms for construction supply chain management in the internet environment International Journal of Project Management, 25(2), 150-157. 